\title{
Preservation of Animal Cadavers with a Formaldehyde-free Solution for Gross Anatomy
}

\author{
Lynda Tamayo-Arango $^{1}$ Anderson Garzón-Alzate ${ }^{1}$ \\ 1 Veterinary Medicine School, CIBAV Research Group, Faculty of \\ Agrarian Sciences of Universidad de Antioquia, Medellin, \\ Antioquia, Colombia

\begin{abstract}
Address for correspondence Lynda Tamayo-Arango, MV, MSc, DSc, Facultad de Ciencias Agrarias, Universidad de Antioquia, Ciudadela Robledo, Cra 75 No. 65-87, Bloque 46-123, Medellin 050000, Antioquia, Colombia (e-mail: lynda.tamayo@udea.edu.co).
\end{abstract}

J Morphol Sci 2018;35:136-141.

\begin{abstract}
Motivated by the current health safety regulations at Universidad de Antioquia, our laboratory changed the animal cadavers preserving solution based on formaldehyde, methanol, glycerin and phenol to a formula based on $85 \%$ ethanol, $10 \%$ glycerin, and $5 \%$ benzalkonium chloride. A total of 33 donated cadavers were preserved with this formula so far: 4 goats, 16 dogs, 3 cats and 10 bovine fetuses. Red and blue latex dyes were injected into the vascular systems. Small cadavers were first injected with latex, followed by muscular and intracavitary injection with the preservation fluid and immersion in $96 \%$ ethanol. Large cadavers were vascularly injected, wrapped in plastic bags and vascularly repleted with latex during the next 8 days. Samples were taken for microbiological analysis from 3 cadavers: 1 cadaver wrapped with plastic for 2 months, 1 cadaver immersed for 4 months, and 1 cadaver after 15 days of perfusion. The first way to preserve cadavers was

Keywords

- dissection

- embalming

- ethanol

- fixation

- formaldehyde

- preservation more time-consuming, but it rendered cadavers with a more thorough distribution of latex on small arteries and veins. An enhanced flexibility of joints and tissues promoted an easier dissection process, even of the most distal regions, allowing the movement of tendons along their sheaths. Also, a better color preservation was observed in spite of a darkening after the tissues were exposed to the air. There was no gross evidence of decay from bacterial or fungal growth, and the cultures were negative. The most important advantage of this formula is its lower toxicity and cost.
\end{abstract}

\section{Introduction}

The study of gross anatomy using cadavers is an important educational tool that should be available in anatomy laboratories. ${ }^{1}$ Cadavers for long-term use must be preserved in a way that allows students to see the anatomical structures in prosections and during dissection, maintaining as much as possible their color and flexibility. Formaldehyde is the tissue fixative generally used, alone or mixed with other agents, such as phenol, glycerin and methanol. The mixtures generally intend to diminish as much as possible the quantity of formaldehyde used and to amend some deficiencies of formaldehyde, such as its poor antifungal activity and rigidity. ${ }^{2}$

The mixture of alcohols for preservation, called soft embalming, helps the tissues to retain their natural appear- ance. They have been used in the training of surgeons, maximizing the benefit of the dissection and of the performance of procedures, according to Benet et al (2014). ${ }^{4,5}$ One of the best soft-preservation techniques is the Thiel embalming technique, in which the tissue remains flexible and preserves color. Nevertheless, it is difficult and expensive to implement. ${ }^{6}$ However, the Thiel and Benet embalming techniques contain $2 \%$ formaldehyde ${ }^{5}$ and has been reported as toxic, corrosive, carcinogenic, mutagenic and with an objectionable odor. ${ }^{7}$

Another soft-preservation technique is the mixture of ethanol with glycerin ${ }^{8}$ and thymol, ${ }^{9}$ with no addition of formaldehyde. Soft-fixed cadavers can be more easily dissected due to the ease of removal of the skin and of the superficial fascia and to a good differentiation of tissue planes. ${ }^{4}$ received

July 24, 2017

accepted

August 3, 2018

published online

August 27, 2018
DOI https://doi.org/

10.1055/s-0038-1669434.

ISSN 2177-0298.
Copyright $\odot 2018$ by Thieme Revinter

Publicações Ltda, Rio de Janeiro, Brazil
License terms

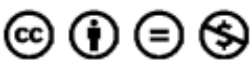


There is an increasing concern about the use of formaldehyde in anatomy laboratories, because of its high toxicity, in particular its carcinogenicity, ${ }^{10}$ its irritating properties on mucous membranes, ${ }^{11}$ and its alleged neuropsychological effects. ${ }^{12}$ Other risks of formaldehyde are the potential for pulmonary impairment and extrinsic asthma, ${ }^{11}$ and skin irritation. ${ }^{13}$ According to Viegas et $\mathrm{al}^{14}{ }^{14}$ anatomy students, staff and professors are exposed to formaldehyde concentrations greater than 5 ppm during their stay in the laboratory. ${ }^{15}$

In our laboratory, a study from 2012 showed a range of formaldehyde concentrations between 0.19 and $0.5 \mathrm{ppm}$. In another study from 2014, the range was between 0.31 and $10 \mathrm{ppm},{ }^{16,17}$ much higher than the threshold limit value ceiling (TLV-C) of $0.3 \mathrm{ppm}$, or $0.37 \mathrm{mg} / \mathrm{m}^{3} .{ }^{10}$ After this report, the manager of occupational hazards of the university ruled the closure of the laboratory unless the formaldehyde were lowered to acceptable levels. Closing the anatomy laboratories in medical schools would impact anatomy training and affect the clinical and surgical skills of future practitioners. ${ }^{8}$

At the time, we were using a mixture of formalin (15\%), phenol (10\%), methanol (5\%) and glycerin (15\%). In spite of these high levels of formaldehyde and the use of phenol, we had a big problem with fungus contamination in the cadavers, probably due to the high temperatures (up to $28^{\circ} \mathrm{C}$ ) and to the high relative humidity (up to $73 \%$ ) in the city of Medellin. Therefore, it became an imperative to use preserving solutions with nontoxic agents that would provide a safer environment for the students, the laboratory assistants and the academic staff. The aim of the present report was to describe the efficacy of a mixture to preserve animal cadavers.

\section{Materials and Methods}

The cadavers used in our laboratory belonged to the Willed Body Donation Program of the Faculty of Agrarian Sciences of Universidad de Antioquia. All the cadavers were frozen after death and thawed 24 hours before the preservation procedure. Since 2014, 33 cadavers had been prepared as follows: 4 goats, 16 dogs, 3 cats and 10 bovine fetuses.

The formula used to preserve the cadavers was made of industrial ethanol (85\%), glycerin (10\%), and benzalkonium chloride ( $5 \%$; from a $50 \%$ solution). To highlight the vascular system, some of the cadavers were injected with latex dyes (Texbond SBR, Colorquímica SA, Medellín, Colombia), blue for veins (Azul Novaprint SP-BR, Colorquímica SA, Medellín, Colombia), which was injected in the jugular vein, and red for arteries (Escarlata Novaprint SP-RY, Colorquímica SA, Medellin, Colombia), which was injected in the carotid artery. The injection of dye was made until the color was seen in peripheral locations such as the pinna, the conjunctiva, the tongue or the paws, or until the vessels started to bulge.

The cadavers were prepared in two different ways, depending on their size:

1) If the cadaver was small (weight $<15 \mathrm{~kg}$ ), colored latex was injected before the preservation procedure. The quantity of latex injected corresponded approximately to $5 \%$ of body weight of the cadaver. The specimen was maintained at $4^{\circ} \mathrm{C}$ overnight and then injected with the preservation solution directly into the muscles, into the subcutaneous space and into the body cavities in a uniform and systematic way. An incision in the abdominal ventral midline was made and the cadaver was immersed only in 96\% ethanol (benzalkonium chloride not included in the immersion solution).

2) Suitable for both small ( $<15 \mathrm{~kg}$ ) and large ( $>15 \mathrm{~kg}$ ) cadavers. The solution was injected directly on the carotid artery and a small incision in the jugular vein was made to allow for blood drainage. When there was no more blood draining, the jugular vein was ligated and the solution was perfused until the cadaver was turgid; it was then wrapped in a plastic bag. During the next 8 days, colored latex was injected. The quantity of latex injected was lower than in the former procedure. After 15 days and during the dissection work, the cadaver was submerged on $50 \%$ ethanol (cadaver weight $<15 \mathrm{~kg}$ ) or left on the dissecting table carefully wrapped in a plastic bag to prevent desiccation (cadaver weight $>15 \mathrm{~kg}$ ). The large cadavers were not submerged due to the space limitations in our laboratory.

The large cadavers were not elected for the first procedure because the injection of the preserving solution would be too time-consuming for such a large volume of tissue to be preserved and due to the necessity of submerging the cadaver. The cause of death has to be considered to decide on the method of preservation and on the vascular injection of latex. Polytraumatized cadavers should not be injected with latex due to the high probability of leaking in the body cavities. Also, these cadavers have to be intramuscularly and intracavitary injected with the fixative solution.

It was noted that when cadavers were left on the table after perfusion, a considerable quantity of fluid leaked onto the table. Samples were taken from this fluid to measure the percentage of alcohol with an alcoholmeter calibrated to $20^{\circ} \mathrm{C}$.

To evaluate the possible growth of microorganisms, several samples (swabs) were taken from 3 cadavers: 1 dog cadaver wrapped with plastic for 2 months, 1 dog cadaver taken out from submersion (left on submersion for 4 months) and 1 dog cadaver with 15 days of preparation. Samples were taken from the eyes, the mouth, the paws, the local of incision for perfusion (in the cervical region) and from between muscles (on dissected specimens). The samples were analyzed in the diagnostic laboratory of the Faculty of Agrarian Sciences, University of Antioquia.

The manager of occupational hazards of our university measured the concentration of alcohol in the air in a simulation of a laboratory in full use (cadavers unwrapped in all the 12 tables of the laboratory) to evaluate the potential risk of explosion.

A cost analysis was made comparing the former solution used in the laboratory based on formaldehyde with the new formula based on ethanol.

\section{Results}

The first way to preserve cadavers was more time-consuming, but it rendered cadavers with a more thorough 


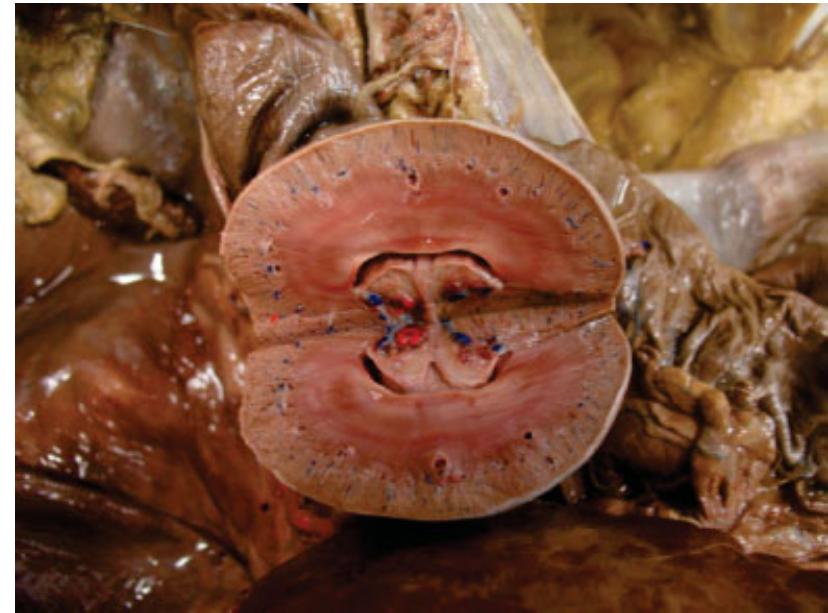

Fig. 1 Soft-preserved dog kidney. Good preservation of contrast between the medulla and the cortex of the kidney, with colored latex highlighting arteries (red) and veins (blue).

distribution of the latex dye on small arteries and veins than the second procedure, probably because the preserving solution dehydrates the cadaver and produces shrinkage of the lumen of the small vessels ( $\mathbf{- F i g s .} \mathbf{1}$ and $\mathbf{2}$ ). Liquid leaked from the cadavers during the first 15 days and had a very low concentration of alcohol (0-15\%), which is an indication of the dehydration process of the cadaver.

When dissection started with a cadaver, the color of the muscles was much more reddish than of the cadavers fixed with formaldehyde mixtures. Also, the color of the viscera was better preserved. However, when the tissues were exposed to air during the dissection, they got darker (-Fig. 3).

The process of dissection of the cadavers preserved with the new formula is much more comfortable, due to the lack of offensive odors. The skin, muscles and viscera maintained their natural appearance, with a slight hardening of the tissues. Due to the preserved flexibility of the joints, it was possible to dissect the most distal parts of the extremities, such as the flexor digitorum superficialis, the manica flexoria

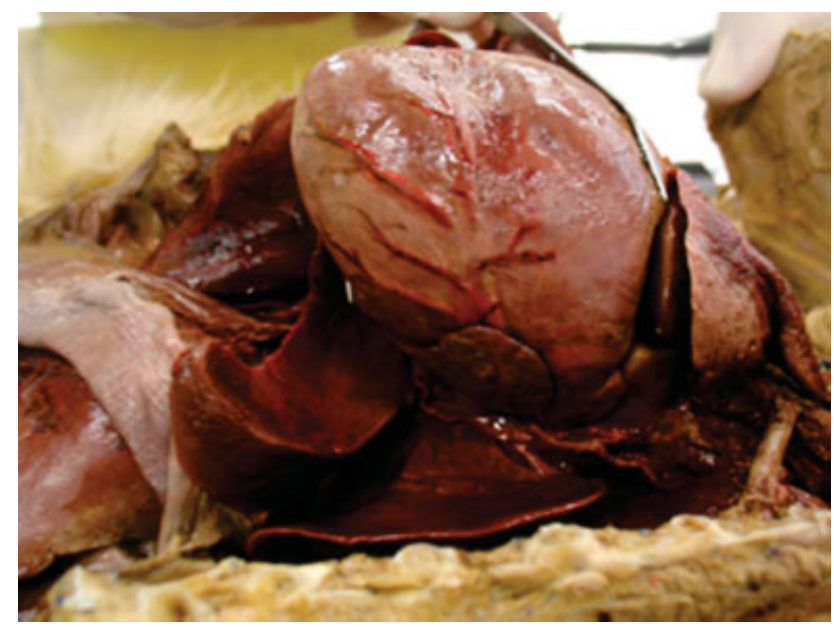

Fig. 2 Soft-preserved dog heart. Almost life-like appearance of viscera in a prosected dog cadaver injected with latex.

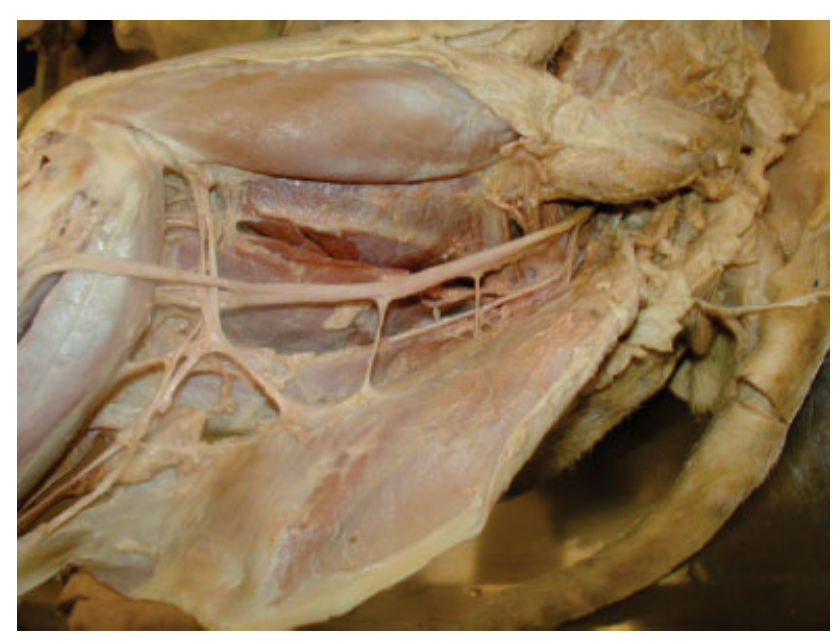

Fig. 3 Soft-preserved and dissected posterior dog leg. Color contrast could be seen in this photograph, between the tissue already exposed to air with brown color and the tissue recently exposed with reddish color.

and the flexor digitorum profundus tendons in a cadaver as small as a $4 \mathrm{~kg}$ poodle dog, with the possibility of moving the articulation and see the glide of the tendons on their sheath (-Fig. 4 and -Supplementary Videos S1 and S2 (online only)). A poor preservation of the brain was observed.

\section{Supplementary Video S1}

Tendon sliding along manica flexoria. Online content including video sequences viewable at: www.thiemeconnect.com/products/ejournals/html/10-1055-s0038-1669434-jms-1211-v1.mp4.

\section{Supplementary Video S2}

Easy knee movement. Online content including video sequences viewable at: www.thieme-connect.com/ products/ejournals/html/10-1055-s-0038-1669434jms-1211-v2.mp4.

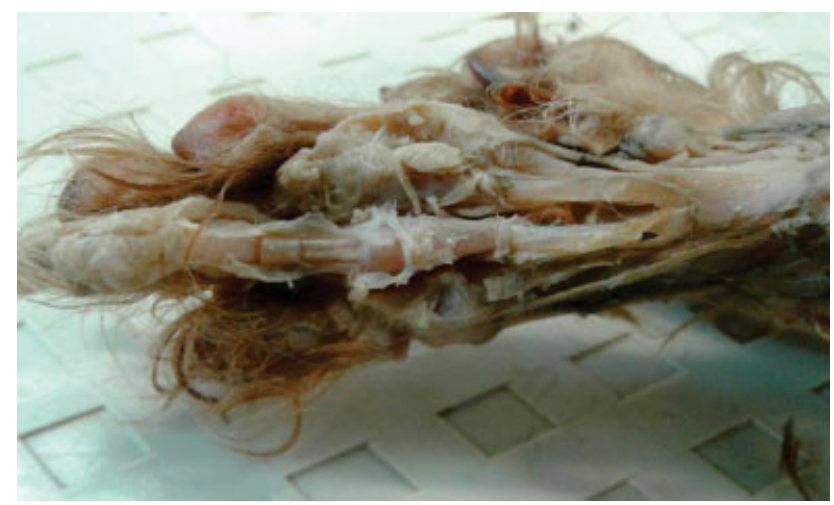

Fig. 4 Distal dog forelimb. Fine dissection of flexor tendons and of the manica flexoria in a $4 \mathrm{~kg}$ poodle cadaver. 
Table 1 Cost analysis of soft-embalming and hard-embalming mixtures

\begin{tabular}{|c|c|c|c|c|}
\hline Agents & $\begin{array}{l}\text { Cost / liter } \\
\text { (COP) }\end{array}$ & $\begin{array}{l}\text { Amount } \\
\text { (liters) }\end{array}$ & $\begin{array}{l}\text { Cost for } 20 \text { liters of } \\
\text { the solution (COP) }\end{array}$ & $\begin{array}{l}\text { Cost for } 20 \text { liters of } \\
\text { the solution (USD) }\end{array}$ \\
\hline \multicolumn{5}{|l|}{ Soft-embalming } \\
\hline Ethanol & 4,369 & 17 & 74,272 & 24 \\
\hline Glycerin & 7,852 & 2 & 15,704 & 5 \\
\hline \multirow[t]{2}{*}{ Benzalkonium chloride } & 8,277 & 1 & 8,277 & 3 \\
\hline & & & Total: 98,253 & Total: 32 \\
\hline \multicolumn{5}{|l|}{ Hard-embalming } \\
\hline Formalin & 2,730 & 3 & 8,191 & 3 \\
\hline Glycerin & 7,852 & 3 & 23,556 & 8 \\
\hline Methanol & 2,827 & 1 & 2,827 & 1 \\
\hline Phenol (1 kg) & 124,700 & 2 & 249,400 & 81 \\
\hline Water & 100 & 11 & 1,100 & 0.4 \\
\hline Total & & & Total: 285,074 & Total: 93 \\
\hline
\end{tabular}

Abbreviations: COP, Colombian pesos; USD, US dollars.

All the prepared cadavers are still in our laboratory in good condition, either submerged or wrapped on tables. The cadavers are being used for several groups of students for dissection work and as prosected specimens, and there is no evidence of contamination or decay. None of the cadavers showed any gross evidence of microbial contamination, and cultures failed to grow bacteria or fungi.

Cadavers exposed for a long time to the air became dehydrated, for example, during the dissection process. To avoid this dehydration, besides submerging or wrapping the cadaver, the students were encouraged to hydrate it with saline water $0.9 \%$.

In the simulation of a class with all cadavers unwrapped on the tables, the air concentration of ethyl alcohol ranged from 0.0 to $107.92 \mathrm{mg} / \mathrm{m}^{3}{ }^{18}$

The comparative cost analysis showed that the ethanolglycerin-benzalkonium chloride solution was $65.5 \%$ cheaper than the formalin-phenol-methanol-glycerin solution (-Table 1).

\section{Discussion}

The aspect of tissues and organs fixed with ethanol-glycerinbenzalkonium chloride are closer to the natural state than that of those fixed with formalin. The dissection process was facilitated because the tissues are not too flexible, as when they are fresh, but not too hardened, as when they are fixed with formaldehyde. Other authors have reported the use of ethanol fixation in human ${ }^{8,9}$ and animal cadavers. ${ }^{19}$ In our experience, the ethanol-glycerin-benzalkonium chloride fixation is very suitable for the dissection work of students, which is in agreement with Hammer et $\mathrm{al}^{7}$ and Turan et al. ${ }^{19}$

Color preservation is convenient for dissection, because it helps the students to the better identify the different structures. Qualitatively, we perceive a more reddish color in the muscles and viscera when starting the dissection. However, future research needs to uncover why the exposure to air affects so much the color and how to preserve it better. Turan et $\mathrm{al}^{19}$ measured the color of soft-preserved cadavers with a spectrophotometer and found that the tissues took on a whitish hue, with a posterior change to a greenish hue, but in the present case, the change of color was attributed to the use of citric acid and liquid foam soap.

An ethanol-glycerin solution can be used for anatomical fixation and conservation without serious health effects. ${ }^{9}$ No teratogenic effects of ethanol-glycerin fumes have been reported, ${ }^{7}$ which makes this preserving solution suitable to the work of pregnant women in the anatomy laboratory. ${ }^{9}$ These characteristics of ethyl alcohol show greater advantages compared with formaldehyde.

For a better preservation of the tissues, we added benzalkonium chloride to the mixture, taking advantage of its biocidal activity. ${ }^{20}$ In this method, phenol is substituted by benzalkonium chloride in its antifungal activity, without the high toxicity and mutagenic effects of benzalkoniu chloride. ${ }^{21}$ The most important hazard of benzalkonium chloride is an irritating effect on direct contact to the eyes and the skin. ${ }^{22}$ Consequently, the use of safety glasses and gloves became mandatory to all staff and students working and studying in the laboratory.

Mutagenic effects and developmental toxicity are reported for benzalkonium chloride. This risk is higher by inhalation from its solid form. However, in the diluted form and in the concentration used in the formula reported here (with a final concentration of $2.5 \%$ ), it is very unlikely to cause toxicity by inhalation, especially when considering the low vapor pressure $\left(130 \mathrm{mP}\right.$ at $20^{\circ} \mathrm{C}$ ) and the high boiling point $\left(100^{\circ} \mathrm{C}\right)$ of this agent. ${ }^{22}$

Benzalkonium chloride is no longer included for the immersion phase, which is made exclusively with ethanol. This is an outstanding advantage because the solution can be safely discarded with no risk of contaminating refused water 
from the laboratory. Nonetheless, even though the security sheet of benzalkonium chloride does not mention potential impacts of ecotoxicity, ${ }^{22}$ some studies mention effects on phytoplankton and microalgae. ${ }^{23}$

We have found a poor brain fixation in most of the cadavers. A reason for the poor central nervous system (CNS) preservation in the present report could be the fact that the cadavers used were frozen after death and thawed 24 hours before the fixation procedure. It is known that freezing and thawing damage tissues through the formation of crystals that ruptures membranes and causes cell lysis. ${ }^{24}$ According to Hammer et $\mathrm{al}^{7}$, an intrathecal application of formaldehyde is necessary for optimal CNS fixation and preservation in human cadavers.

We have managed to fix tissues with perfusion without the need to immerse them, although some authors report that the immersion is needed to attain a full fixation of the cells. ${ }^{8}$ We did not need to apply formaldehyde because no signs of autolysis were seen, unlike the communication of Hammer et $\mathrm{al}^{9}$, who reported the need to apply $0.35 \%$ formaldehyde. It is necessary to take into account that Hammer et $\mathrm{al}^{9}$ fixated human cadavers, while we worked with animal cadavers with a maximum weight of $35 \mathrm{~kg}$.

The growing of fungi on the skin and organs is very common in cadavers preserved with formaldehyde, ${ }^{25}$ and it was a very serious problem in our laboratory in the past. The capacity of a fixative solution to eliminate previously present microorganisms in the cadaver and to avoid the growing of bacteria and fungi is very important for the safety of the students and of the faculty during the dissection work. ${ }^{26}$ Two studies reported microbiological examinations using ethanol fixative solutions on animal cadavers. ${ }^{27}$ They found single colonies of Pseudomonas oryzihabitans, Chryseobacterium sp., Acinetobacter sp. from the lungs, and Micrococcus sp. and Bacillus sp. from one muscle sample, while Turan et $\mathrm{al}^{19}$ found only some nonpathogenic Bacillus species. According to our results, the ethanol-glycerin-benzalkonium chloride mixture showed no growth of either bacteria or fungi. However, the samples taken were limited in number, so it will be necessary to enlarge the samples for microbiological cultures in future research to better evaluate this aspect.

Our results for the measures of ethyl alcohol concentration in the air are very low. The threshold limit value short term exposure limit (TLV-STEL) for ethyl alcohol is $1,880 \mathrm{mg} / \mathrm{m}^{3}$, therefore the resulting risk index is very low $(0.0$ to 0.1$) .{ }^{18}$ The principal motivation for this measurement was the explosion risk, ${ }^{28}$ which was discarded. Therefore, ethanol-glycerin fixation is well suited for dissection workshops held in rooms with poor ventilation, as stated by Hammer et al. ${ }^{7}$

According to Hammer et al $(2015 ; 2012),{ }^{7,9}$ ethanol solutions are much more expensive than formaldehyde. ${ }^{9}$ However, in the overall cost analysis reported in the present study, the ethanol-glycerin-benzalkonium chloride solution was $65.5 \%$ cheaper than the formalin-phenol-methanol-glycerin solution traditionally used in many laboratories.

Since we started using the new formula in our laboratory, staff and students have not been exposed to formaldehyde or other toxic fumes. This fact is more significant for faculty members, because they are the most affected due to longtime exposure in laboratory work.

\section{Conclusions}

Based on a combination of several preserving solutions reported in the literature, we have developed a mixture that is easy to do and inexpensive, obtaining good results for the long-term use of prosected cadavers in laboratory sessions, as well as in the dissection work of students. The great advantages of this fixative-preserving mixture are the flexibility and color preservation, and its low toxicity.

\section{Contributions of Authors}

L. Tamayo-Arango and A. Garzón-Alzate both made the information research, the ideation of the formula, the description of the results and edited the manuscript.

\section{Conflicts of Interest}

None to declare.

\section{Acknowledgments}

We want to acknowledge Martha Olivera and Juana Vidal for the microbial and fungal cultures made in the diagnostic laboratory of the Faculty of Agrarian Sciences, University of Antioquia.

\section{References}

1 Cornwall J, Stringer MD. The wider importance of cadavers: educational and research diversity from a body bequest program. Anat Sci Educ 2009;2(05):234-237

2 Sri-Indrasutdhi V, Ueapattanakit J, Sommatas A. Investigation of airborne fungi and their ability to grow on formalin-fixed human cadavers. Mycosphere 2015;6(06):729-736

3 Benet A1, Rincon-Torroella J, Lawton MT, González Sánchez JJ. Novel embalming solution for neurosurgical simulation in cadavers. J Neurosurg 2014;120(05):1229-1237

4 Eisma R, Lamb C, Soames RW. From formalin to Thiel embalming: What changes? One anatomy department's experiences. Clin Anat 2013;26(05):564-571

5 Ottone NE, Vargas CA, Fuentes R, Del Sol M. Walter Thiel's Embalming Method. Review of Solutions and Applications in Different Fields of Biomedical Research. Int J Morphol 2016;34 (04):1442-1454

6 Jaung R, Cook P, Blyth P. A comparison of embalming fluids for use in surgical workshops. Clin Anat 2011;24(02):155-161

7 Hammer N, Löffler S, Bechmann I, Steinke H, Hädrich C, Feja C. Comparison of modified Thiel embalming and ethanol-glycerin fixation in an anatomy environment: Potentials and limitations of two complementary techniques. Anat Sci Educ 2015;8(01):74-85

8 Hammer N, Löffler S, Feja C, Bechmann I, Steinke H. Substitution of formaldehyde in cross anatomy is possible. J Natl Cancer Inst 2011;103(07):610-611

9 Hammer N, Löffler S, Feja C, et al. Ethanol-glycerin fixation with thymol conservation: a potential alternative to formaldehyde and phenol embalming. Anat Sci Educ 2012;5(04):225-233

10 NTP (NATIONAL TOXICOLOGY PROGRAM). Final report on carcinogens background document for formaldehyde. Report on carcinogens background document for formaldehyde. 2010, n. 10-5981: p.i.

11 Wolkoff P, Nielsen GD. Non-cancer effects of formaldehyde and relevance for setting an indoor air guideline. Environ Int 2010;36 (07):788-799 
12 Yu J, Su T, Zhou T, et al. Uric formaldehyde levels are negatively correlated with cognitive abilities in healthy older adults. Neurosci Bull 2014;30(02):172-184

13 Takahashi S, Tsuji K, Fujii K, et al. Prospective study of clinical symptoms and skin test reactions in medical students exposed to formaldehyde gas. J Dermatol 2007;34(05):283-289

14 Viegas S, Ladeira C, Nunes C, et al. Genotoxic effects in occupational exposure to formaldehyde: A study in anatomy and pathology laboratories and formaldehyde-resins production. J Occup Med Toxicol 2010;5(01):25

15 Ryan TJ, Burroughs GE, Taylor K, Kovein RJ. Video exposure assessments demonstrate excessive laboratory formaldehyde exposures. Appl Occup Environ Hyg 2003;18(06):450-457

16 Amaya-Gonzalez LF, Lenis-Muñetón JF, Pérez-Osorno MM. Evaluación de Formaldehído Laboratorio de Anatomía Animal Facultad de Ciencias Agrarias Universidad De Antioquia. Trabajo de práctica académica Especialización en Salud Ocupacional. Cohorte 18. Universidad de Antioquia Facultad Nacional de Salud Pública, 2012, p. 15.

17 Osorio-Giraldo B. Informe Técnico Monitoreo Gases de Lectura Directa Concentración de Formaldehído en Aire. Laboratorio de Higiene y Toxicología Industrial Regional Occidente. Positiva Compañía de Seguros S.A. ARL, 2014, p. 14.

18 Osorio-Giraldo B. Informe de evaluaciones ocupacionales. Diagnóstico de alcoholes. Positiva Compañía de Seguros S.A. ARL, 2016, p. 15.

19 Turan E, Gules O, Kilimci FS, et al. The mixture of liquid foam soap, ethanol and citric acid as a new fixative-preservative solution in veterinary anatomy. Ann Anat 2017;209(01):11-17
20 Thorsteinsson T, Loftsson T, Masson M. Soft antibacterial agents. Curr Med Chem 2003;10(13):1129-1136

21 Murray AR, Kisin E, Castranova V, Kommineni C, Gunther MR, Shvedova AA. Phenol-induced in vivo oxidative stress in skin: evidence for enhanced free radical generation, thiol oxidation, and antioxidant depletion. Chem Res Toxicol 2007;20(12):1769-1777

22 MSDS. Safety Data Sheet - Benzalkonium chloride 5\%. SR0212. [June 7, 2017]. Available from http://www.oxoid.com/pdf/msds/ EN/SR0212.pdf

23 Pérez P, Fernández E, Beiras R. Toxicity of benzalkonium chloride on monoalgal cultures and natural assemblages of marine phytoplankton. Water Air Soil Pollut 2009;201(1-4):319-330

24 Schäfer AT, Kaufmann JD. What happens in freezing bodies? Experimental study of histological tissue change caused by freezing injuries. Forensic Sci Int 1999;102(2-3):149-158

25 Janczyk P, Weigner J, Luebke-Becker A, Kaessmeyer S, Plendl J. Nitrite pickling salt as an alternative to formaldehyde for embalming in veterinary anatomy-A study based on histo- and microbiological analyses. Ann Anat 2011;193(01):71-75

26 Tabaac B, Goldberg G, Alvarez L, Amin M, Shupe-Ricksecker K, Gomez F. Bacteria detected on surfaces of formalin fixed anatomy cadavers. Ital J Anat Embryol 2013;118(01):1-5

27 Janczyk P, Weigner J, Luebke-Becker A, Richardson KC, Plendl J. A pilot study on ethanol-polyethylene glycol-formalin fixation of farm animal cadavers. Berl Munch Tierarztl Wochenschr 2011; 124(5-6):225-227

28 OSHA. Ethyl alcohol. Exposure limits and health effects. [March 7, 2017]. Retrieved from https://www.osha.gov/dts/chemicalsampling/data/CH_239700.html 